\title{
Fish consumption, not fatty acid status, is related to quality of life in a healthy population
}

Citation for published version (APA):

Schiepers, O., De Groot, R., Jolles, J., \& Van Boxtel, M. (2010). Fish consumption, not fatty acid status, is related to quality of life in a healthy population. Prostaglandins Leukot Essent Fatty Acids, 83(1), 31-35.

https://doi.org/10.1016/j.plefa.2010.02.030

DOI:

10.1016/j.plefa.2010.02.030

Document status and date:

Published: 01/07/2010

Document Version:

Peer reviewed version

Please check the document version of this publication:

- A submitted manuscript is the version of the article upon submission and before peer-review. There can be important differences between the submitted version and the official published version of record. People interested in the research are advised to contact the author for the final version of the publication, or visit the DOI to the publisher's website.

- The final author version and the galley proof are versions of the publication after peer review.

- The final published version features the final layout of the paper including the volume, issue and page numbers.

Link to publication

\section{General rights}

Copyright and moral rights for the publications made accessible in the public portal are retained by the authors and/or other copyright owners and it is a condition of accessing publications that users recognise and abide by the legal requirements associated with these rights.

- Users may download and print one copy of any publication from the public portal for the purpose of private study or research.

- You may not further distribute the material or use it for any profit-making activity or commercial gain

- You may freely distribute the URL identifying the publication in the public portal.

If the publication is distributed under the terms of Article 25fa of the Dutch Copyright Act, indicated by the "Taverne" license above, please follow below link for the End User Agreement:

https://www.ou.nl/taverne-agreement

Take down policy

If you believe that this document breaches copyright please contact us at:

pure-support@ou.nl

providing details and we will investigate your claim.

Downloaded from https://research.ou.nl/ on date: 26 Apr. 2023 


\title{
Fish consumption, not fatty acid status, is related to quality of life in a healthy population
}

\author{
O.J.G. Schiepers ${ }^{\mathrm{a}, *}$, R.H.M. de Groot ${ }^{\mathrm{a}, \mathrm{b}}$, J. Jolles ${ }^{\mathrm{a}, \mathrm{b}}$, M.P.J. van Boxtel $^{\mathrm{a}}$ \\ a School for Mental Health and Neuroscience (MHeNS)/European Graduate School for Neuroscience (EURON), Department of Psychiatry and Neuropsychology, Maastricht \\ University, P.O. Box 616, 6200 MD Maastricht, The Netherlands \\ ${ }^{\mathrm{b}}$ AZIRE Research Institute, Faculty of Psychology and Education, VU University, Amsterdam, The Netherlands
}

\section{A R T I C L E I N F O}

\section{Article history:}

Received 20 May 2009

Received in revised form

30 September 2009

Accepted 12 February 2010

\section{Keywords:}

Fish consumption

Fatty acids

Mental health

Quality of life

Population-based study

\begin{abstract}
A B S T R A C T
Depressive symptoms in the community have a considerable impact on quality of life. Although longchain polyunsaturated fatty acids (LCPUFA) have frequently been implicated in depressed mood, their relationship with quality of life has scarcely been investigated.

This study examined the cross-sectional associations between fish consumption and plasma phospholipid LCPUFA status on the one hand, and quality of life, as measured by the Short Form 36 questionnaire, on the other in a population-based sample. The mental health component of quality of life was not associated with LCPUFA status or fish consumption. Fish consumption showed a positive association with physical well-being, which remained significant after correction for LCPUFA status, suggesting that the relationship between fish consumption and physical well-being is independent of the LCPUFA content of fish. These findings indicate that fish consumption may serve as a proxy for a healthy lifestyle or a favorable nutritional status, which is reflected in better quality of life.
\end{abstract}

(c) 2010 Elsevier Ltd. All rights reserved.

\section{Introduction}

Depressive symptoms are highly prevalent in the general population [1]. Subclinical depressive symptoms not only significantly increase the risk of developing major depression [2,3], but are also associated with considerable functional impairment $[2,4]$. The negative impact of subclinical depressive symptoms on both physical and mental functioning is generally reflected in a reduction of quality of life $[5,6]$. From a public health perspective, it is important to identify the factors involved in the development of depressive symptoms and the concomitant decrease in quality of life.

It has often been suggested that long-chain polyunsaturated fatty acids (LCPUFA), which are primarily found in fish, may lower the risk of developing depressive symptoms [7-9]. Strikingly, the relationship between LCPUFA status and quality of life has scarcely been investigated-only one study has addressed this issue to date. In a community-based study, Crowe et al. [10] examined the associations between serum phospholipid LCPUFA status and the physical and mental health components of quality of life. Although the authors did not find any associations between mental well-being and the two LCPUFA that are predominant in fish, i.e. eicosapentaenoic acid (EPA, 20:5n-3) and docosahexae-

\footnotetext{
* Corresponding author. Tel.: +31 433881027; fax: +31 433884092.

E-mail address: olga.schiepers@np.unimaas.nl (O.J.G. Schiepers).
}

noic acid (DHA, 22:6n-3), they did find a positive relationship between EPA concentration and physical well-being. In addition, Silvers and Scott [11] addressed the relationships between fish consumption and the physical and mental health dimensions of quality of life in a population-based sample. Interestingly, this study reported a positive relationship between fish consumption and self-reported mental health, but not physical well-being.

Unfortunately, the two above-mentioned studies solely focused on either LCPUFA status or fish consumption, which makes it difficult to compare their results. An additional limitation of the study by Silvers and Scott is the crude distinction between fish consumers and non-consumers, without taking into account the frequency and/or the kind of fish consumption.

The aim of the present study was to investigate the crosssectional relationships between LCPUFA status, fish intake, and quality of life in a population-based sample. In order to compensate for the limitations of the above-mentioned studies, we included detailed measurements of both fish consumption and plasma phospholipid LCPUFA concentrations in our study.

\section{Patients and methods}

\subsection{Design and study population}

The present study was part of a longitudinal research program investigating the determinants and consequences of cognitive 
aging, the Maastricht Aging Study (MAAS) [12]. Participants were randomly drawn from a register of family practices [13]. Medically verified exclusion criteria at baseline were chronic neurological pathology, psychiatric disorders, mental retardation, and psychotropic drug use. The study population consisted of 1823 participants, aged 24-81 years at baseline, and comprised four demographically identical panels, each stratified for age, sex, and general ability level. A detailed description of the MAAS study design can be found elsewhere [12,14].

The present study was carried out in one single panel of the MAAS study, consisting of 470 participants at baseline, of whom 301 individuals participated in the 12 -year reassessments. During the follow-up period, 169 participants dropped out due to a variety of reasons, including death, serious illnesses, and refusal to participate. The most common reasons for refusal were "being too occupied", "feeling too ill", and "participation is too timeconsuming" [15]. Dropouts did not differ from the remaining participants in terms of age, sex, level of education, marital status, alcohol consumption, smoking, and body mass index (BMI). At 12year follow-up, habitual fish consumption and quality of life were measured by means of questionnaires. Participation in a sidearm study that involved blood sampling was voluntary; venous blood was collected from 241 individuals in order to determine individual LCPUFA status. Sixty individuals refused to donate blood. Volunteers did not differ from the other participants in the panel in terms of age, sex, and level of education. The study was approved by the local Medical Ethics Committee. Prior to enrolment all participants signed an informed consent form.

\subsection{Quality of life assessment}

The Short Form 36 Health Survey (SF-36) is a generic, healthrelated quality of life questionnaire based on self-report [16]. It is composed of thirty-six items, organized into eight multi-item scales measuring physical well-being (physical functioning, role limitations due to physical problems, bodily pain, and general health perception) and mental well-being (vitality, social functioning, role limitations due to emotional problems, and mental health) over the past four weeks. The raw scale scores were standardized and aggregated into a Physical Component Summary score and a Mental Component Summary score [17]. The two summary scores range from 0 to 100 , with higher scores indicating better quality of life.

\subsection{Fatty acid status}

Plasma was separated from blood cells by centrifugation and collected in tubes, which were closed under nitrogen and stored at $-80^{\circ} \mathrm{C}$ until fatty acid analysis. Fatty acid profiles of phospholipids isolated from venous plasma were determined as described before [18]. Total phospholipid-associated fatty acid concentrations are expressed as $\mathrm{mg} / \mathrm{L}$ plasma, and relative fatty acid concentrations as percentages of the total amount of phospholipid-associated fatty acids (\%wt/wt). Forty-two fatty acids were identified. In the present study, five fatty acids were considered of interest, i.e. arachidonic acid (AA, 20:4n-6), EPA, and DHA, which are implicated in physical and mental health [19-21], the DHA status parameter adrenic acid (AdrA, 22:4n-6), and docosapentaenoic acid (DPA, 22:5n-3), which is a major intermediate in EPA-to-DHA conversion.

\subsection{Fish consumption}

Fish consumption was measured by means of a validated short self-report questionnaire [22]. Fish types were categorized according to DHA content, as DHA is the predominant LCPUFA in fish [23]: low (fish fingers, prawns, pickled herring, cod, mussels, plaice, tuna, and tilapia), intermediate (trout, raw herring, smoked eel, smoked salmon, and canned salmon), and high (smoked herring, herring in tomato sauce, mackerel, canned sardines, and salmon). Frequency of consumption (never, once a month, two to three times a month, once a week, and more often than once a week) was used to calculate fish consumption within each category: $0,1,2,4$, and 8 for the 'low DHA' category; 0, 2, 4, 8 , and 16 for the 'intermediate DHA' category; and $0,3,6,12$, and 24 for the 'high DHA' category. Total fish consumption corresponded to the sum of the scores of the three DHA categories. Overall fish consumption scores range from 0 to 48 , indexing a dimensionless estimate of fish intake.

\subsection{Sociodemographic and lifestyle variables}

Age, sex, level of education (low/high), marital status (married or living together/not married), alcohol consumption (low/high), smoking (yes/no), and BMI $\left(\mathrm{kg} / \mathrm{m}^{2}\right)$ were treated as covariates [24-27]. Level of education, measured by classifying formal schooling according to the Dutch educational system [28], was categorized into 'low' (primary education-junior vocational education) or 'high' (higher secondary education-university education). Alcohol consumption, measured by means of a short self-report questionnaire, was dichotomized into 'low' or 'high' according to WHO standards [29]. High alcohol intake corresponded to the consumption of at least two (women) or three (men) alcoholic beverages (standard units, i.e. $8 \mathrm{~g}$ ethanol per drink) per day on average.

\subsection{Statistical analysis}

Normal P-P plots indicated skewness of EPA concentration and fish consumption, which was corrected by log-transformation. Pearson's product-moment correlations were calculated for all variables. Hierarchical linear regression analyses were performed to investigate the associations between fish consumption or the five fatty acids of interest on the one hand and quality of life on the other. Separate regression models were fitted for the Physical and Mental Component Summary scores of the SF-36, adjusting for age, sex, level of education, marital status, alcohol consumption, smoking, and BMI in the first step. The primary predictor variables, the LCPUFA (Model 1) or fish consumption (Model 2), were entered in step 2. In a third model, the associations between fish consumption and quality of life were additionally adjusted for the LCPUFA, in order to investigate whether the putative associations between fish consumption and quality of life were attributable to the LCPUFA content of fish. To this end, the covariates were entered in step 1, the LCPUFA in step 2, and fish consumption in step 3 .

Statistical differences were considered significant at $p$-values $<0.05$. A power calculation assuming a small effect size of 0.04 [30] revealed a statistical power of 0.86. All analyses were performed using SPSS 16.0 for Apple Macintosh (SPSS Inc., Chicago, IL).

\section{Results}

Data on quality of life and plasma phospholipid LCPUFA concentrations were available for 233 individuals, and information concerning fish consumption was available for 231 participants. The participants' characteristics are summarized in Table 1. The scores (mean \pm SD) on the eight scales of the SF-36 were 
$82.7 \pm 21.1$ for physical functioning, $81.0 \pm 33.0$ for role limitations due to physical problems, $80.3 \pm 20.2$ for bodily pain, $67.2 \pm 18.5$ for general health perception, $69.9 \pm 17.1$ for vitality, $86.0 \pm 18.6$ for social functioning, $88.7 \pm 26.9$ for role limitations due to emotional problems, and $79.6 \pm 15.5$ for mental health. These scores were comparable to the age and genderadjusted means obtained in the Dutch population [31]. The SF-36 Physical Component Summary scores ranged from 14.7 to 64.8, and the Mental Component Summary scores ranged from 8.8 to 69.9 .

Fish consumption was positively correlated with the plasma phospholipid concentrations of the n-3 fatty acids EPA (Pearson's $r=0.293, p<0.001)$ and DHA $(r=0.520, p<0.001)$, and negatively correlated with the $n-6$ fatty acid AdrA $(r=0.232, p<0.001)$. The correlations between fish consumption and AA, and between fish consumption and DPA were not significant $(r=0.105, p=0.110$ and $r=-0.106, p=0.110$, respectively). The plasma phospholipid concentrations of the fatty acids of interest fell within the normal

Table 1

Participants' characteristics.

\begin{tabular}{ll}
\hline & Total sample $(n=233)$ \\
\hline Age (years) & $60.0(36-88)$ \\
Female sex (\%) & 50.6 \\
Low level of education (\%) & 70.8 \\
Married (\%) & 79.0 \\
High alcohol consumption (\%) & 6.0 \\
Current smoker (\%) & 23.2 \\
BMI (kg/m ${ }^{2}$ ) & $26.3 \pm 4.3$ \\
Physical Component Summary score & $48.7 \pm 9.7$ \\
Mental Component Summary score & $53.6 \pm 8.7$ \\
Fish consumption ${ }^{\mathrm{a}}$ & $8.6(0-44)$ \\
AA (\%wt/wt) & $9.62 \pm 2.12$ \\
EPA (\%wt/wt) & $0.99 \pm 0.49$ \\
DHA (\%wt/wt) & $3.45 \pm 1.04$ \\
AdrA (\%wt/wt) & $0.29 \pm 0.08$ \\
DPA (\%wt/wt) & $0.93 \pm 0.19$ \\
\hline
\end{tabular}

Values are expressed as mean \pm SD, mean (range), or \%; BMI, body mass index; $A A$ arachidonic acid (20:4n-6); EPA, eicosapentaenoic acid (20:5n-3); DHA, docosahexaenoic acid (22:6n-3); AdrA, adrenic acid (22:4n-6); DPA, docosapentaenoic acid $(22: 5 n-3)$

${ }^{\mathrm{a}} n=231$.

${ }^{b}$ Fatty acid concentrations are expressed as percentages of the total amount of plasma phospholipid-associated fatty acids. range for a community-based population, as compared to other studies $[8,32]$.

Table 2 shows the results of the hierarchical linear regression analyses. After correction for age, sex, level of education, marital status, alcohol consumption, smoking, and BMI, no significant associations were identified between the Mental Component Summary score of the SF-36 and the LCPUFA concentrations, nor fish consumption. The SF-36 Physical Component Summary score showed no significant associations with the fatty acids of interest, whereas a significant positive relationship with fish consumption was found. The association between fish consumption and the Physical Component Summary score remained significant after additional correction for the LCPUFA (Model 3) (Table 2). With respect to the sociodemographic and lifestyle variables, being married was positively related to mental well-being ( $p=0.025$ in Model 1 and $p=0.021$ in Model 2), whereas age and BMI negatively predicted physical well-being $(p=0.012$ and $p<0.001$ in Model 1, and $p=0.003$ and $p<0.001$ in Model 2, respectively).

\section{Discussion}

The present study suggests that fish consumption, but not LCPUFA status, is related to quality of life in the general population. The relationship between fish consumption and quality of life appears to apply specifically to the dimension of physical well-being, and seems to be independent of the fatty acid content of fish. We found no associations between mental wellbeing and neither LCPUFA status nor fish consumption.

The lack of a relationship between LCPUFA concentrations and subjective mental health is in agreement with the populationbased study performed by Crowe et al. [10], in which no associations between LCPUFA status and mental well-being were found. However, with respect to physical well-being, the authors reported a positive association with serum phospholipid EPA concentrations. Although no associations between LCPUFA concentrations and physical well-being were identified in our study, we did find a positive relationship between fish consumption and physical well-being. Unfortunately, data on fish consumption were not included in the study by Crowe et al., which restricts comparison with the present findings.

Our findings oppose the results of the study conducted by Silvers and Scott [11], in which a positive relationship between

Table 2

Associations between quality of life and plasma phospholipid LCPUFA concentrations or fish consumption.

\begin{tabular}{|c|c|c|c|c|c|}
\hline Dependent variable & Independent variable & & $R^{2}$ step $1^{\text {a }}$ & $R^{2}$ change step 2 & $R^{2}$ change step 3 \\
\hline \multicolumn{6}{|c|}{ Physical Component Summary Score } \\
\hline & LCPUFA status ${ }^{\mathrm{b}}$ & Model 1 & $0.185^{* *}$ & 0.009 & \\
\hline & Fish consumption & Model 2 & $0.187^{* *}$ & $0.015^{*}$ & \\
\hline & & Model 3 & $0.187^{* *}$ & 0.007 & $0.016^{*}$ \\
\hline \multicolumn{6}{|c|}{ Mental Component Summary Score } \\
\hline & LCPUFA status & Model 1 & 0.054 & 0.009 & \\
\hline & Fish consumption & Model 2 & 0.053 & 0.000 & \\
\hline & & Model 3 & 0.053 & 0.010 & 0.001 \\
\hline
\end{tabular}

LCPUFA=long-chain polyunsaturated fatty acid.

${ }^{\text {a }} R^{2}$ represents the proportion of explained variance, and $R^{2}$ change represents the change in the proportion of explained variance after each step in hierarchical linear

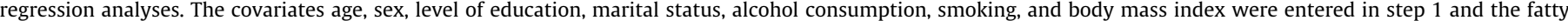

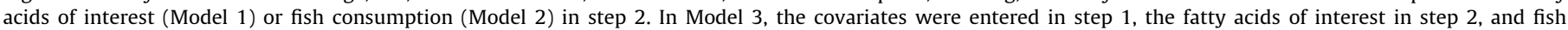
consumption in step 3.

${ }^{\mathrm{b}}$ LCPUFA status comprises arachidonic acid (20:4n-6), eicosapentaenoic acid (20:5n-3), docosahexaenoic acid (22:6n-3), adrenic acid (22:4n-6), and docosapentaenoic acid $(22: 5 n-3)$.

$* p<0.05$.

** $p<0.01$. 
fish consumption and mental rather than physical well-being was reported. Their study showed considerable limitations, however, as fish consumption was recorded on a dichotomous rather than a continuous scale, and their study sample contained relatively few non-fish consumers $(n=87)$ compared to the number of regular fish eaters $(n=4557)$. In addition, LCPUFA concentrations were not measured.

The present finding that fish consumption, but not LCPUFA status, may be related to physical well-being in the general population suggests that frequent dietary intake of fish may exert a beneficial effect on subjective physical health regardless of its fatty acid content. Indeed, no associations between the LCPUFA and physical well-being were found, despite significant correlations between fish intake and the plasma phospholipid concentrations of DHA and EPA. Furthermore, the relationship between fish consumption and physical well-being remained significant after correction for LCPUFA status. It may therefore be argued that other nutrients present in fish, such as vitamins and antioxidants [33], might be responsible for the observed association with physical well-being.

Alternatively, fish consumption may also be related to physical health in a more indirect manner, since another, and perhaps more plausible, possibility is that high fish intake may serve as a proxy for a healthy lifestyle or a generally more favorable nutritional status, e.g. resulting from a Mediterranean diet $[34,35]$. It should be noted, however, that due to the crosssectional nature of the current study, it cannot be ruled out that poor physical health may lead to changes in dietary habits, including decreased fish intake.

The relationships between quality of life and either LCPUFA concentrations or fish consumption may be confounded by a number of variables, including age, sex, BMI, and marital status $[24,26,27]$. The present analyses were corrected for the potential confounders that we considered most likely to influence the associations studied. Altogether, the covariates accounted for up to $19 \%$ of the statistical variance in the regression models, which indicates a large effect [30]. The remaining part of the variance may be explained by predictors of physical and mental well-being that may not be confounders of the studied associations, such as employment status, demography, and social participation, as well as any measurement error associated with the independent and dependent variables.

The additional variance explained by fish consumption in the final regression model was $1.6 \%$, which represents a small effect size [30]. To illustrate the strength of the observed association, as indicated by the standardized regression coefficient for fish consumption $(\beta=0.151)$, an increase in fish consumption by one SD (6.9) corresponds to an increase in Physical Component Summary score by 1.5 points. For example, this implies a 1.5 points higher score on physical well-being for someone increasing the consumption of fish of the intermediate DHA category from 'once a week' to 'more often than once a week'. When the predictive value of fish consumption for physical well-being is compared to the relationship with age $(\beta=-0.183)$ in the same regression model, a one SD increase in fish consumption corresponds to the physical well-being of an individual 11 years younger.

Quality of life is a complex concept, with various dimensions. The use of the SF-36 questionnaire for evaluating the physical and mental dimensions of quality of life is generally accepted, and its validity and reliability have been demonstrated in many populationbased studies [e.g. 31,36-38]. Not only was the SF-36 administered in the present study because of its wide acceptance as an appropriate instrument for the assessment of quality of life, it also facilitated the comparison of our findings with the results reported by Crowe et al. [10] and Silvers and Scott [11], as these authors also used the SF-36 for assessing physical and mental well-being.
The self-report questionnaire that was used to determine fish consumption has recently been validated in our study population [22]. By taking into account the frequency as well as the specific kind of fish consumed, it provides a relatively detailed measure of habitual fish intake, which goes beyond a mere categorization into fish consumers or non-consumers. A general limitation associated with food frequency questionnaires, however, is the fact that they provide an estimate of individual nutrient intake rather than the exact amounts of nutrients consumed. Although our questionnaire has been proven a reliable measure of LCPUFA intake from fish $[22,39]$, and strong correlations were found between fish consumption and DHA or EPA concentrations in the present study, the possibility of measurement error cannot be ruled out completely.

Because our study was part of the 12-year follow-up assessments of MAAS, we investigated whether selective attrition might have biased our results. As our study population did not differ from the dropouts in terms of the baseline characteristics age, sex, level of education, marital status, alcohol consumption, smoking, and BMI, we consider this possibility unlikely.

The present study has several strengths. First, we used a non-clinical sample with a broad age range, which increased the external validity of our study. Although our study population was about 10-20 times smaller than the samples used by Crowe et al. and Silvers and Scott, the statistical power of the present study was sufficiently large to detect associations even with small effect sizes. Hence, we consider it unlikely that using a larger sample size would have yielded different results in terms of the nature and the direction of the effects observed. Second, both fish consumption and LCPUFA concentrations were measured, thereby enabling the comparison of these two dietary factors in relation to the different dimensions of quality of life. Moreover, these variables were measured on an interval (fish consumption) or on a continuous (LCPUFA) scale rather than a categorical scale. This not only increased the statistical power of the analyses, but also allowed for a more accurate description of the associations studied. Finally, we corrected our statistical analyses for a number of sociodemographic and lifestyle variables that were considered potential confounders, which contributed to the internal validity of the study by reducing the chance of a type I error.

Similar to the two above-mentioned studies, our study was limited by its cross-sectional nature, which does not allow for inferences about the causality of the observed relationship between fish consumption and quality of life.

Summarizing, the present study indicates that fish consumption, but not LCPUFA status, may be related to quality of life in the general population. More specifically, fish consumption appears to be associated with subjective physical health rather than mental well-being. This differential finding suggests that fish consumption may serve as a proxy for a healthy lifestyle or a favorable nutritional status, which is reflected in better quality of life. Prospective studies are needed to investigate the causality of the observed relationship between fish consumption and quality of life.

\section{Acknowledgements}

Fatty acid analyses were financially supported by EFAMOL Ltd. (Brackenholme, Selby, North Yorkshire, UK).

\section{References}

[1] R.C. Kessler, S. Zhao, D.G. Blazer, M. Swartz, Prevalence, correlates, and course of minor depression and major depression in the National Comorbidity Survey, J. Affect Disord. 45 (1997) 19-30. 
[2] P. Cuijpers, R. de Graaf, S. van Dorsselaer, Minor depression: risk profiles, functional disability, health care use and risk of developing major depression, J. Affect Disord. 79 (2004) 71-79.

[3] E. Horwath, J. Johnson, G.L. Klerman, M.M. Weissman, What are the public health implications of subclinical depressive symptoms?, Psychiatr Q. 65 (1994) 323-337.

[4] M.H. Rapaport, L.L. Judd, Minor depressive disorder and subsyndromal depressive symptoms: functional impairment and response to treatment, J. Affect Disord. 48 (1998) 227-232.

[5] R.D. Goldney, L.J. Fisher, E. Dal Grande, A.W. Taylor, Subsyndromal depression: prevalence, use of health services and quality of life in an Australian population, Soc. Psychiatry Psychiatr. Epidemiol. 39 (2004) 293-298.

[6] A.F. Da Silva Lima, M.P. De Almeida Fleck, Subsyndromal depression: an impact on quality of life?, J Affect Disord. 100 (2007) 163-169.

[7] A. Tanskanen, J.R. Hibbeln, J. Tuomilehto, et al., Fish consumption and depressive symptoms in the general population in Finland, Psychiatry Serv. 52 (2001) 529-531.

[8] H. Tiemeier, H.R. van Tuijl, A. Hofman, A.J. Kiliaan, M.M. Breteler, Plasma fatty acid composition and depression are associated in the elderly: the Rotterdam Study, Am. J. Clin. Nutr. 78 (2003) 40-46.

[9] S.M. Conklin, S.B. Manuck, J.K. Yao, J.D. Flory, J.R. Hibbeln, M.F. Muldoon, High omega-6 and low omega-3 fatty acids are associated with depressive symptoms and neuroticism, Psychosom. Med. 69 (2007) 932-934.

[10] F.L. Crowe, C.M. Skeaff, T.J. Green, A.R. Gray, Serum phospholipid n 3 longchain polyunsaturated fatty acids and physical and mental health in a population-based survey of New Zealand adolescents and adults, Am. J. Clin. Nutr. 86 (2007) 1278-1285.

[11] K.M. Silvers, K.M. Scott, Fish consumption and self-reported physical and mental health status, Public Health Nutr. 5 (2002) 427-431.

[12] J. Jolles, P.J. Houx, M.P.J. van Boxtel, R.W.H.M. Ponds (Eds.), The Maastricht Aging Study: Determinants of Cognitive Aging, Neuropsych Publishers, Maastricht, The Netherlands, 1995.

[13] J.F.M. Metsemakers, P. Höppener, J.A. Knottnerus, R.J.J. Kocken, C.B.G. Limonard, Computerized health information in The Netherlands: a registration network of family practices, Br. J. Gen. Pract. 42 (1992) 102-106.

[14] M.P.J. van Boxtel, F. Buntinx, P.J. Houx, J.F.M. Metsemakers, J.A. Knottnerus, J. Jolles, The relation between morbidity and cognitive performance in a normal aging population, J. Gerontol. A Biol. Med. Sci. 53 (1998) M147-M154.

[15] C.E.M. Van Beijsterveldt, M.P.J. Van Boxtel, H. Bosma, P.J. Houx, F. Buntinx, J. Jolles, Predictors of attrition in a longitudinal cognitive aging study: the Maastricht Aging Study (MAAS), J. Clin. Epidemiol. 55 (2002) 216-223.

[16] J.E. Ware Jr., B. Gandek, Overview of the SF-36 Health Survey and the International Quality of Life Assessment (IQOLA) Project, J. Clin. Epidemiol. 51 (1998) 903-912.

[17] J.E. Ware Jr., M. Kosinski, M.S. Bayliss, C.A. McHorney, W.H. Rogers, A. Raczek Comparison of methods for the scoring and statistical analysis of SF-36 health profile and summary measures: summary of results from the Medical Outcomes Study, Med. Care 33 (1995) AS264-AS279.

[18] R.H.M. de Groot, G. Hornstra, A.C. van Houwelingen, F. Roumen, Effect of alpha-linolenic acid supplementation during pregnancy on maternal and neonatal polyunsaturated fatty acid status and pregnancy outcome, Am. J. Clin. Nutr. 79 (2004) 251-260.

[19] L.A. Horrocks, Y.K. Yeo, Health benefits of docosahexaenoic acid (DHA), Pharmacol. Res 40 (1999) 211-225.

[20] A.P. Simopoulos, Omega-3 fatty acids in inflammation and autoimmune diseases, J. Am. Coll. Nutr. 21 (2002) 495-505.
[21] G. Parker, N.A. Gibson, H. Brotchie, G. Heruc, A.M. Rees, D. Hadzi-Pavlovic, Omega-3 fatty acids in mood disorders, Am. J. Psychiatry 163 (2006) 969-978.

[22] R.H.M. de Groot, M.P.J. van Boxtel, O.J.G. Schiepers, G. Hornstra, J. Jolles, Age dependence of plasma phospholipid fatty acid levels: potential role of linoleic acid in the age-associated increase in docosahexaenoic acid and eicosapentaenoic acid concentrations, Br. J. Nutr. 102 (2009) 1058-1064.

[23] P.M. Kris-Etherton, D.S. Taylor, S. Yu-Poth, et al., Polyunsaturated fatty acids in the food chain in the United States, Am. J. Clin. Nutr. 71 (2000) 179S-188S.

[24] F.L. Crowe, C. Murray Skeaff, T.J. Green, A.R. Gray, Serum n-3 long-chain PUFA differ by sex and age in a population-based survey of New Zealand adolescents and adults, Br. J. Nutr. 99 (2008) 168-174.

[25] J.A. Simon, J. Fong, J.T.J. Bernert, W.S. Browner, Relation of smoking and alcohol consumption to serum fatty acids, Am. J. Epidemiol. 144 (1996) 325-334.

[26] C. Féart, M.A. Jutand, S. Larrieu, et al., Energy, macronutrient and fatty acid intake of French elderly community dwellers and association with sociodemographic characteristics: data from the Bordeaux sample of the ThreeCity Study, Br. J. Nutr. 98 (2007) 1046-1057.

[27] B. Galobardes, A. Morabia, M.S. Bernstein, Diet and socioeconomic position: does the use of different indicators matter?, Int J. Epidemiol. 30 (2001) 334-340.

[28] S.E. de Bie, Standaardvragen 1987: Voorstellen voor uniformering van vraagstellingen naar achtergrondkenmerken en interviews [Standard questions 1987: proposal for uniformization of questions regarding background variables and interviews], Leiden University Press, Leiden, The Netherlands, 1987 (Dutch).

[29] WHO, in: International Guide for Monitoring Alcohol Consumption and related Harm, World Health Organization, Geneva, 2000.

[30] J. Cohen, in: Statistical Power Analysis for the Behavioral Sciences, Erlbaum, Hillsdale, NJ, 1988.

[31] N.K. Aaronson, M. Muller, P.D. Cohen, et al., Translation, validation, and norming of the Dutch language version of the SF-36 Health Survey in community and chronic disease populations, J. Clin. Epidemiol. 51 (1998) 1055-1068.

[32] M. Maes, A. Christophe, J. Delanghe, C. Altamura, H. Neels, H.Y. Meltzer, Lowered omega 3 polyunsaturated fatty acids in serum phospholipids and cholesteryl esters of depressed patients, Psychiatry Res. 85 (1999) 275-291.

[33] C. Berr, T. Akbaraly, J. Arnaud, I. Hininger, A.M. Roussel, P. Barberger Gateau, Increased selenium intake in elderly high fish consumers may account for health benefits previously ascribed to omega-3 fatty acids, J. Nutr. Health Aging 13 (2009) 14-18.

[34] A.P. Simopoulos, The Mediterranean diets: What is so special about the diet of Greece? The scientific evidence, J. Nutr. 131 (2001) 3065S-3073S.

[35] W.C. Willett, The Mediterranean diet: science and practice, Public Health Nutr. 9 (2006) 105-110.

[36] K.L. Haywood, A.M. Garratt, R. Fitzpatrick, Quality of life in older people: a structured review of generic self-assessed health instruments, Qual. Life Res. 14 (2005) 1651-1668.

[37] M.K. Peek, L. Ray, K. Patel, D. Stoebner-May, K.J. Ottenbacher, Reliability and validity of the SF-36 among older Mexican Americans, Gerontologist 44 (2004) 418-425.

[38] B. Ou, H.Q. Guo, J. Liu, Y. Zhang, G. Sun, Reliability and validity testing of the SF-36 Questionnaire for the evaluation of the quality of life of Chinese urban construction workers, J. Int. Med. Res. 37 (2009) 1184-1190.

[39] O.J.G. Schiepers, R.H.M. de Groot, J. Jolles, M.P.J. van Boxtel, Plasma phospholipid fatty acid status and depressive symptoms: association only present in the clinical range, J. Affect Disord. 118 (2009) 209-214. 